\title{
Nuclear fusion reacted inside metals by intense sonoimplantation effect
}

\author{
By Yoshiaki ARATA, M. J. A., ${ }^{\dagger)}$ and Yue-Chang ZHANG \\ Osaka University, 11-1, Mihogaoka, Ibaraki, Osaka 567-0047 \\ (Contributed by Yoshiaki AratA, M. J. A., March 12, 2002)
}

\begin{abstract}
Using intense ultrasonic cavitation effect, metals kept in heavy water were changed to nanometer-sized fine powders and simultaneously condensed a large amount of deuteriums for 1 2 days. Mass analyses of gases released from the remnant metal powders revealed existence of ${ }^{3} \mathrm{He}$ and ${ }^{4} \mathrm{He}$ which were produced by the deuterium nuclear fusion reacted inside the metals. On the other hand, simultaneously generated excess energy were recognized in only $\mathrm{D}_{2} \mathrm{O}$ working liquid, using the working liquids of $\mathrm{D}_{2} \mathrm{O}$ or $\mathrm{H}_{2} \mathrm{O}$-water in which immersed metal foils kept inside a sono-vessel.
\end{abstract}

Key words: Sonoimplantation; sono-powder; D-implantation; H-implantation; sono-solid fusion; sonoexcess energy; sono-helium.

Introduction. Recently, we have investigated on the intense sonoimplantation of various gaseous atoms into metals. ${ }^{1,2)}$ The results showed that many metals (foils of $\mathrm{Ti}, \mathrm{Pd}, \mathrm{Ag}$, Ta, Pt and $\mathrm{Au}$ ) were changed into nanometer-sized powders ("sono-powders") and simultaneously much $\mathrm{D} / \mathrm{H}$-atoms dissociated from the working liquids $\left(\mathrm{D}_{2} \mathrm{O} / \mathrm{H}_{2} \mathrm{O}\right)$ were implanted into their "sonopowders", respectively, and implanted-D atoms ("Dimplantation") were condensed inside the "sono-powders" with much stronger than the "H-implantation". Such intense sonoimplantation effect caused the nuclear fusion to be reacted inside of metals (called shortly "sono-solid fusion").

Experiment. The present experiment was carried out to show generation of the solid-state nuclear fusion ("solid fusion") reacting inside of metals as follows: using a sonoimplantation system as shown in Fig. 1, sonopower of 300 watts with $19 \mathrm{kHz}$ was supplied into the working liquid immersed the metallic foils $(1 \sim 2 \mathrm{~mm} \times$ $1 \sim 2 \mathrm{~mm} \times 0.1 \mathrm{~mm})$. In the first, the sono-vessel was evacuated to about $10^{-3}$ Torr and filled up with the degassed working liquid in which the metallic foils were originally set without the working gas. The metal foils were gradually broken into ultra-fine metal powders ("sono-powders") whose minimum size was less than five nanometer in diameter only after 1 2 days as shown in Photo 1. Secondly, The mass analyses of the sono-pow-

†) Correspondence to: Y. Arata. ders were carried out with a quadrupole mass spectrometer system consisting of three parts: one sample vessel, two Ti-getter pumps, and two type (normal and high resolution) quadrupole mass spectrometers (QMS). The vertical scale of spectrum intensity of $\left(10^{-11}[\mathrm{~A}]\right)$ corresponds to about $\left(3 \times 10^{11}\right)$ in ${ }^{4} \mathrm{He}$. Hereafter the sono-powders of metal $\mathrm{X}$ in working liquids of $\mathrm{D}_{2} \mathrm{O}, \mathrm{H}_{2} \mathrm{O}$ and mixed water are designated as $\mathrm{X}\left[\mathrm{D}_{2} \mathrm{O}\right]$, $\mathrm{X}\left[\mathrm{H}_{2} \mathrm{O}\right]$ and $\mathrm{X}[\mathrm{MIX}]$, respectively, and X[virgin] indicates pure metal $\mathrm{X}$ foil immersed only in the working liquid for 20 hours without ultrasonic irradiation.

Fig. 2 demonstrates a typical example showing difference between the amounts of $\mathrm{D}$ and $\mathrm{H}$ atoms implanted into the $\mathrm{Pd}$ sono-powders, respectively. We have investigated that sono-implanted $\mathrm{H}$ and $\mathrm{D}$ atoms which released from the heated sono-powders form the molecules of hydrides/deuterides dispersed mostly in mass numbers of M1 M50 inside QMS. In these mass numbers, M1 M4 (first group) and M17 M22 (second group) are especially important to know each amount of the sono-implanted H/D atoms. These events were verified clearly using bar graphs of mass numbers (M1 M50) which were measured immediately after finished heating of the sample. ${ }^{1), 2)}$

In present experiment, similar parameters were measured simultaneously with heating of the sample as follows: Fig. 2 (A), B), and (C) show relevant mass intensities as shown in first group (M2, M3, M4 in the upper side diagrams) and second group (M18, M19, M20, M22 


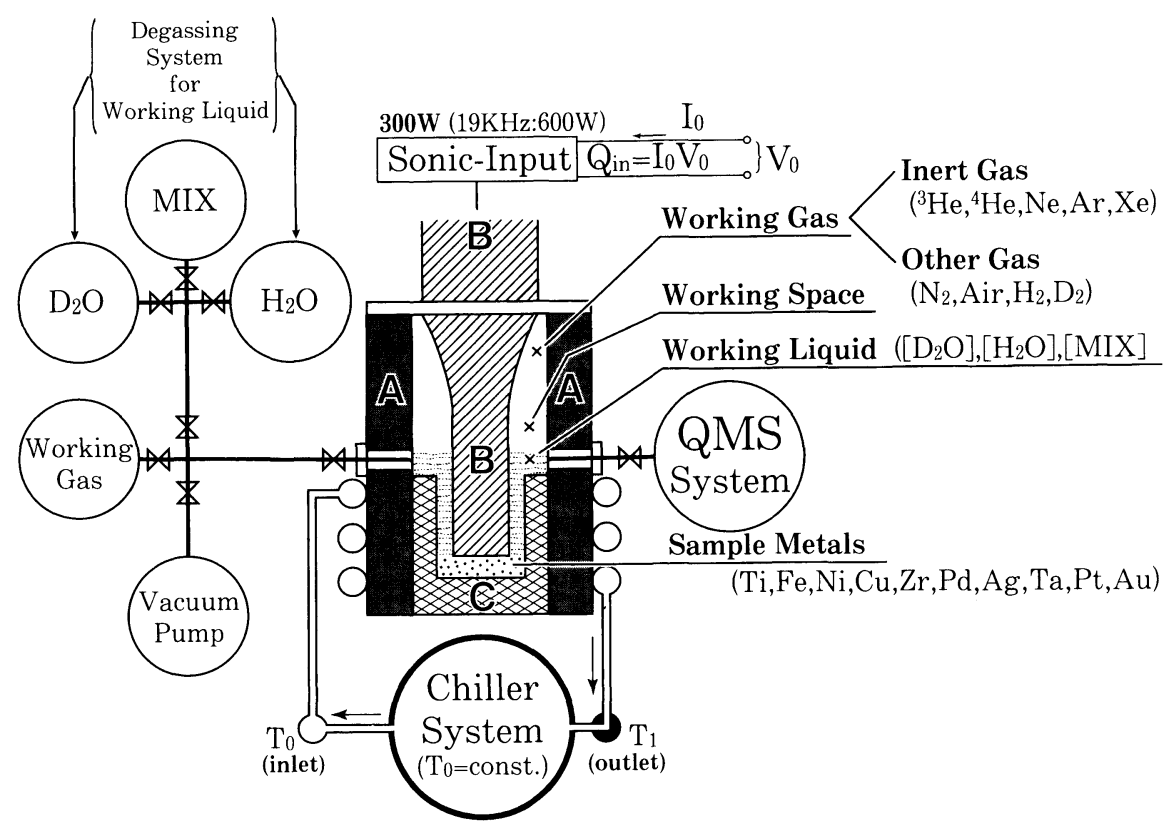

Fig. 1. Schematic diagram of ultrasonic irradiation system included "sono-vessel".

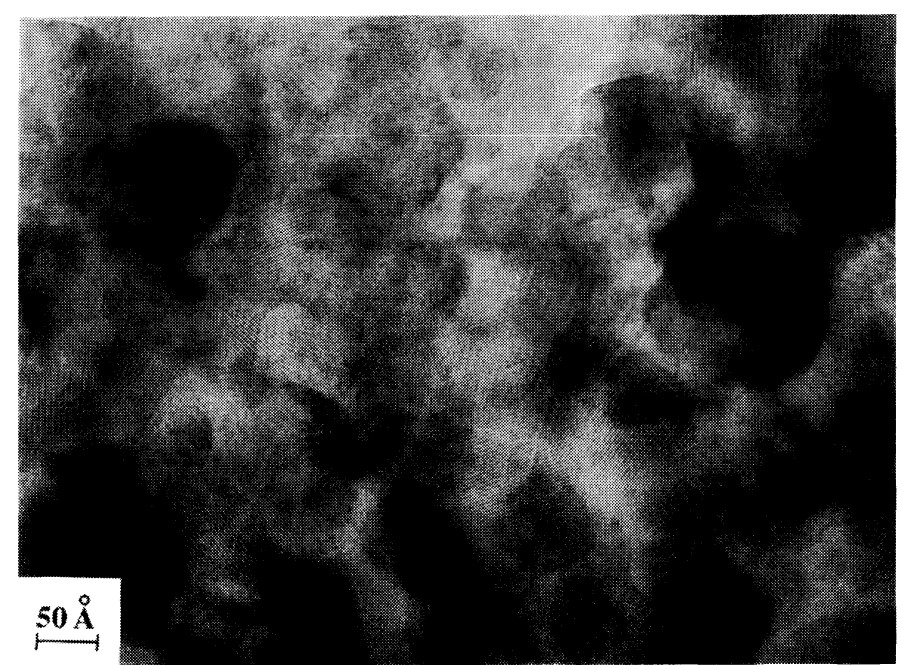

Photo 1. Electron micrograph of the sono-powder $(\mathrm{Au})$ as the typical example.

in the lower side diagrams) in the sono-powders of Pd [virgin], $\mathrm{Pd}\left[\mathrm{H}_{2} \mathrm{O}\right]$ and $\mathrm{Pd}\left[\mathrm{D}_{2} \mathrm{O}\right]$, respectively. The similar behaviors were also displayed in other various metals as shown in Fig. 2 (D) $\left(\mathrm{Ti}\left[\mathrm{D}_{2} \mathrm{O}\right]\right)$ and $(\mathrm{E})\left(\mathrm{Ag}\left[\mathrm{D}_{2} \mathrm{O}\right]\right)$ which were adopted here as the typical examples. As a result, difference between intensities of implanted $\mathrm{D} / \mathrm{H}$ atoms in the sono-powders of Fig. 2 (C) (Pd $\left.\left[\mathrm{D}_{2} \mathrm{O}\right]\right)$ and (B) (Pd $\left.\left[\mathrm{H}_{2} \mathrm{O}\right]\right)$ can be demonstrated by the ratio of spectrum intensity, $\left(\mathrm{Pd}\left[\mathrm{D}_{2} \mathrm{O}\right] / \mathrm{Pd}\left[\mathrm{H}_{2} \mathrm{O}\right]\right)$, at the maximum point on each intensity curve in the relevant mass species such as first group and/or second group as follows:

First group: $\mathrm{F}\left(\frac{\mathrm{D}+\mathrm{DH}+\mathrm{D}_{2}}{\mathrm{H}+\mathrm{DH}+\mathrm{H}_{2}}\right)=\frac{\mathrm{I}(\mathrm{M} 2+\mathrm{M} 3+\mathrm{M} 4)}{\mathrm{I}(\mathrm{M} 1+\mathrm{M} 3+\mathrm{M} 2)} \sim 10$.

Second group:

$$
\mathrm{F}\left(\frac{\mathrm{DO}^{*}+\mathrm{DHO}+\mathrm{D}_{2} \mathrm{O}^{*}}{\mathrm{HO}^{*}+\mathrm{DHO}+\mathrm{H}_{2} \mathrm{O}}\right)=\frac{\mathrm{I}(\mathrm{M} 18+\mathrm{M} 19+\mathrm{M} 20)}{\mathrm{I}(\mathrm{M} 17+\mathrm{M} 19+\mathrm{M} 18)} \sim 1000 .
$$




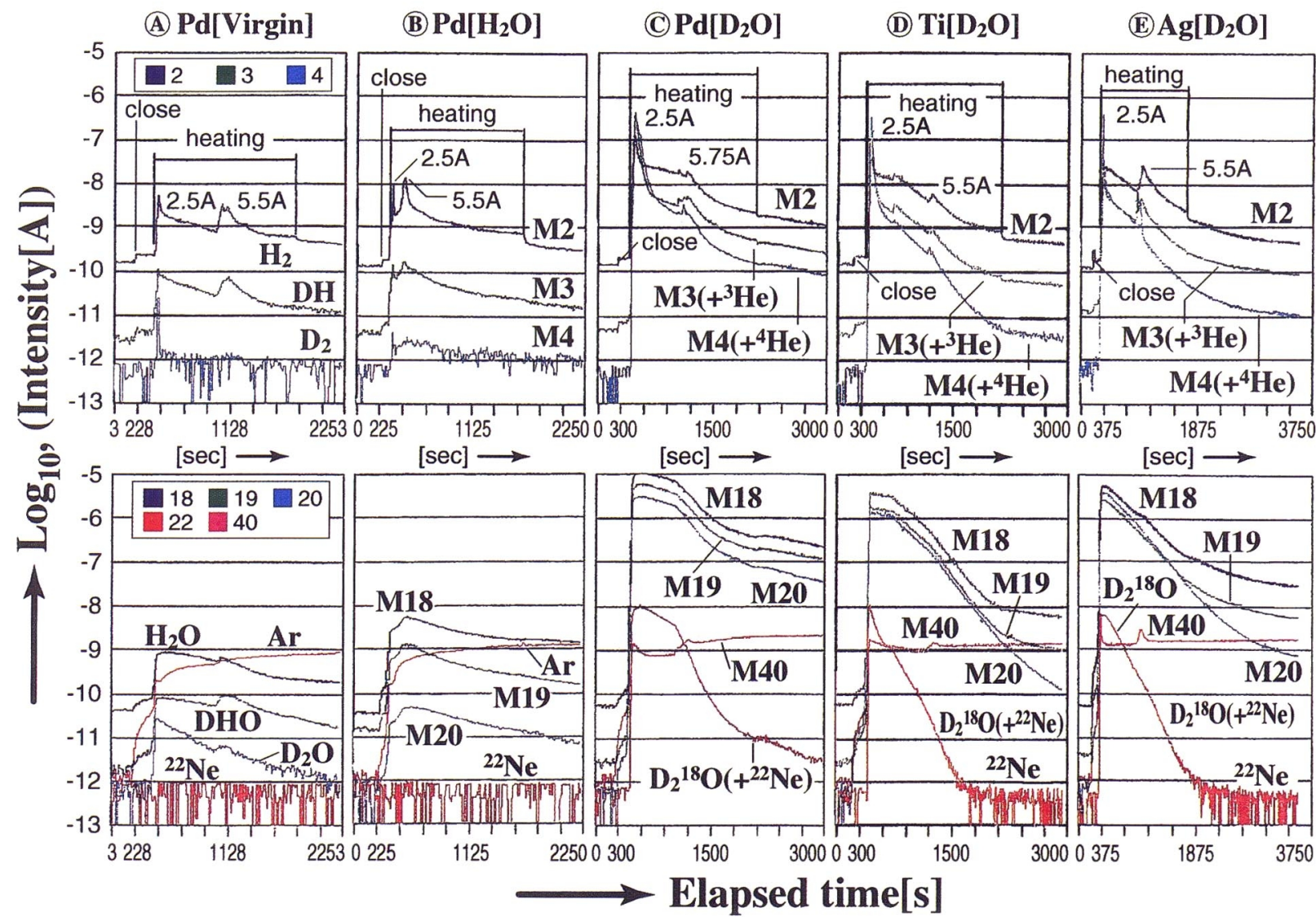

Fig. 2. Chronological changes of QMS intensities of following relevant masses; $\mathrm{M}_{2}, \mathrm{M}_{3}, \mathrm{M}_{4}$ in the upper side diagrams (first group) and $\mathrm{M}_{18}$, $\mathrm{M}_{19}, \mathrm{M}_{20}, \mathrm{M}_{22}$ in the lower side diagrams (second group) in the sono-powders of $\mathrm{Pd}$ [virgin], $\left.\mathrm{Pd}_{2} \mathrm{H}_{2} \mathrm{O}\right], \mathrm{Pd}\left[\mathrm{D}_{2} \mathrm{O}\right], \operatorname{Ti}\left[\mathrm{D}_{2} \mathrm{O}\right]$ and $\mathrm{Ag}\left[\mathrm{D}_{2} \mathrm{O}\right]$.

$A: \mathrm{U}[\mathrm{Pd}]$
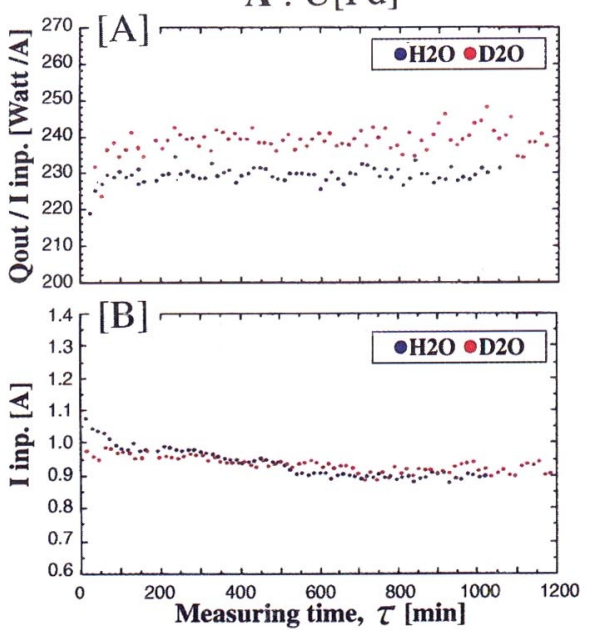

B : U[Ti]
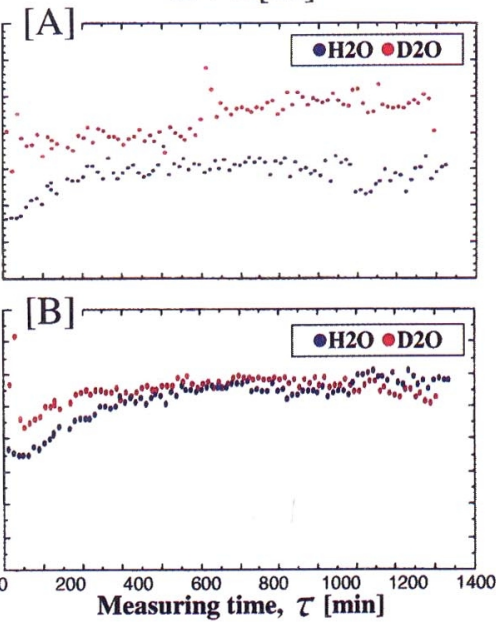

$\mathrm{C}: \mathrm{U}[\mathrm{Au}]$
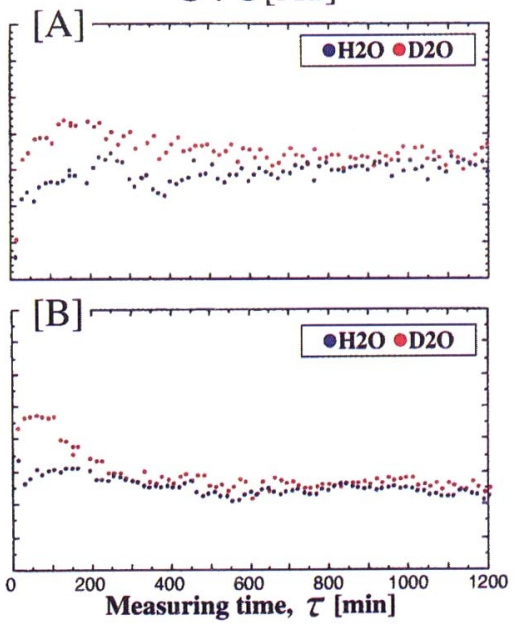

Fig. 3. Relation between sono-generated power and sono-current using sono-working liquids of $\left[\mathrm{D}_{2} \mathrm{O}\right]$ and $\left[\mathrm{H}_{2} \mathrm{O}\right]$. $[\mathrm{A}]$ shows chronological change of each sono-generated power per unit current during formation of sono-powders (A:U[Pd], B:U[Ti], C:U[Au]) in both waters of $\left[\mathrm{D}_{2} \mathrm{O}\right]$ and $\left[\mathrm{H}_{2} \mathrm{O}\right]$, and $[\mathrm{B}]$ shows the chronological change of sono-currents in both waters. 

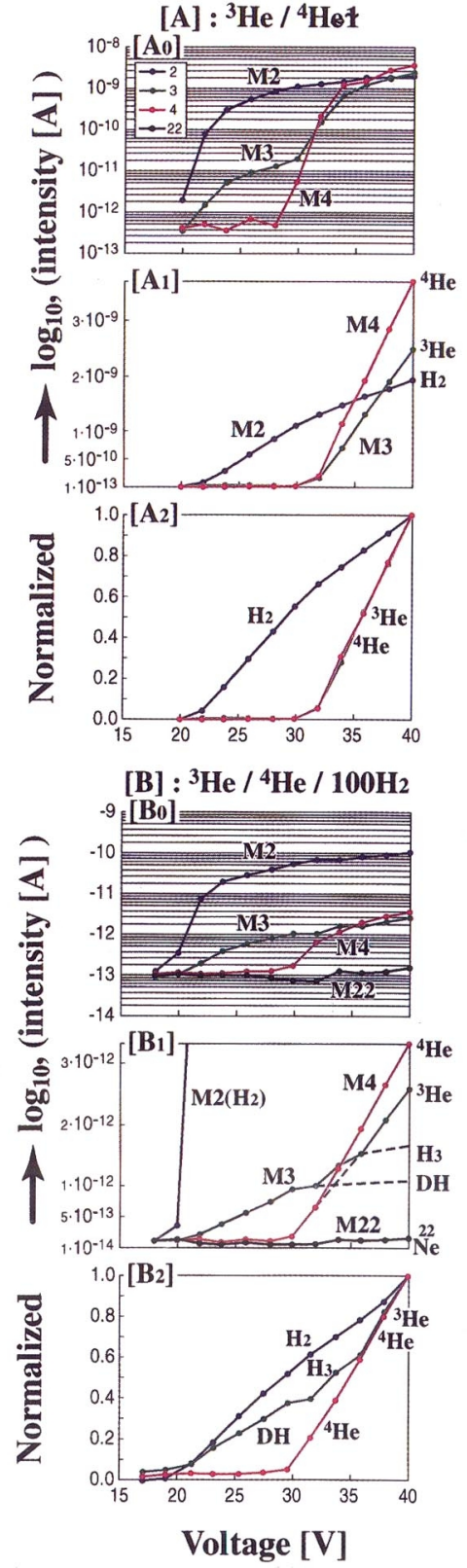

$[\mathrm{C}]: \mathbf{U}[\mathbf{P d}]\left(\mathrm{D}_{2} \mathrm{O}\right)$
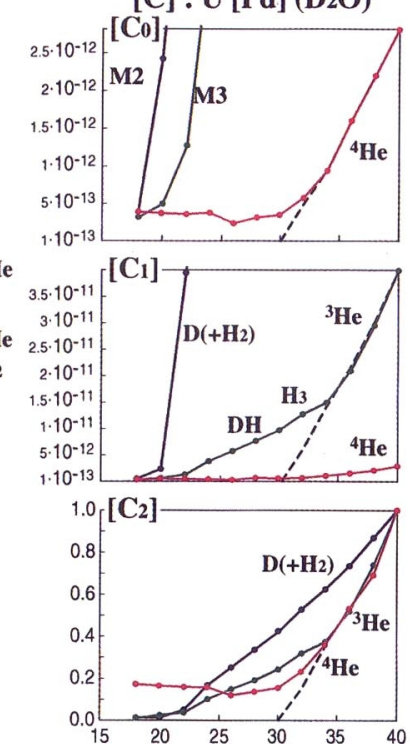

[D] : $\mathrm{U}[\mathrm{Au}]\left(\mathrm{D}_{2} \mathrm{O}\right)$
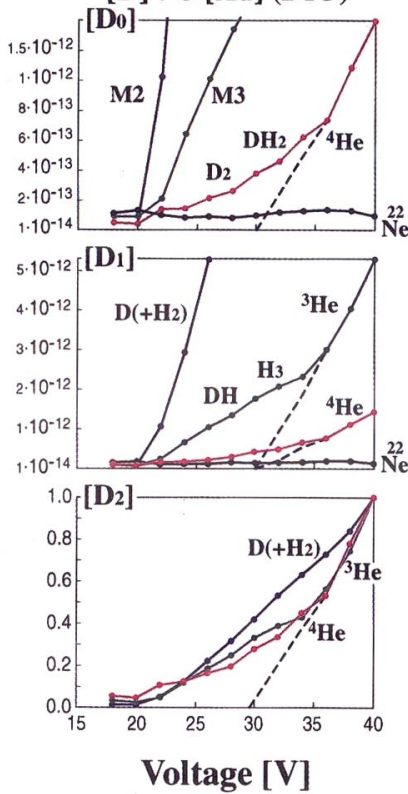

$[\mathrm{E}]: \mathbf{U}[\mathrm{Ti}]\left(\mathrm{D}_{2} \mathrm{O}\right)$
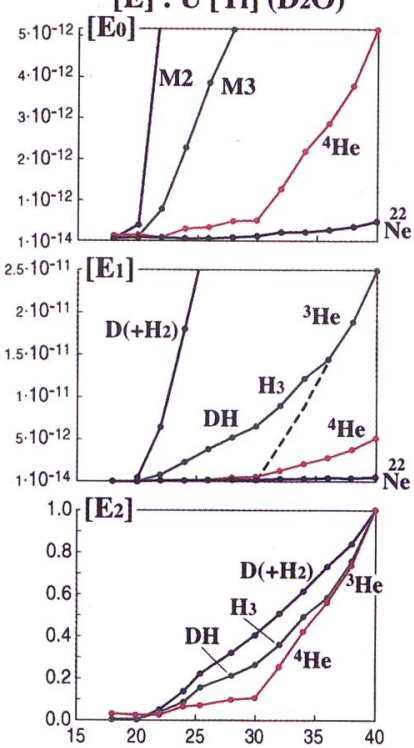

$[\mathrm{F}]: \mathbf{U}[\mathrm{Ag}]\left(\mathrm{D}_{2} \mathrm{O}\right)$
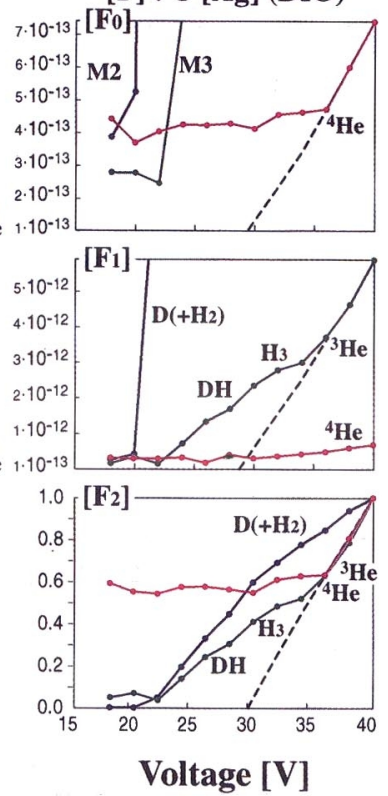

Fig. 4. Relation between applied ionization voltage (V[V]) and spectrum intensity current (I[A]) (called "VI-relation") detected by QMS using the relevant masses $\mathrm{M} 3\left(\mathrm{DH}, \mathrm{H}_{3},{ }^{3} \mathrm{He}\right)$ and $\mathrm{M} 4\left(\mathrm{D}_{2}, \mathrm{DH}_{2},{ }^{4} \mathrm{He}\right)$ in the sono-powders of $\mathrm{Pd}\left[\mathrm{D}_{2} \mathrm{O}\right], \mathrm{Ti}_{2}\left[\mathrm{D}_{2} \mathrm{O}\right], \mathrm{Ag}\left[\mathrm{D}_{2} \mathrm{O}\right]$, and $\mathrm{Au}\left[\mathrm{D}_{2} \mathrm{O}\right]$ as shown in middle and right side columns, $\left(\mathbf{C}_{0}, \mathbf{C}_{1} ; \mathbf{D}_{\mathbf{0}}, \mathbf{D}_{\mathbf{1}} ; \mathbf{E}_{\mathbf{0}}, \mathbf{E}_{1}\right.$ and $\mathbf{F}_{\mathbf{0}}, \mathbf{F}_{\mathbf{1}}$ show "Vi-effect" and also $\mathbf{C}_{\mathbf{2}}, \mathbf{D}_{\mathbf{2}}, \mathbf{E}_{2}, \mathbf{F}_{\mathbf{2}}$ show normalized "Vi-effect"). In left side column, $[\mathrm{A}]$ and $[\mathrm{B}]$ show "VI-relations" of pure heliums (the almost same quantity of ${ }^{3} \mathrm{He}$ and ${ }^{4} \mathrm{He}$ ) and the dillute heliums with 100 times quantity of hydrogen, respectively. ( $\mathbf{A}_{0}$ and $\mathbf{B}_{\mathbf{0}}$ : Spectrum intensity, $\mathbf{A}_{\mathbf{1}}$ and $\mathbf{B}_{\mathbf{1}}$ called "Vi-effect", $\mathbf{A}_{\mathbf{2}}$ and $\mathbf{B}_{\mathbf{2}}$ called normalized "Vi-effect" in the $[\mathrm{A}]$ and $[\mathrm{B}]$, respectively.) These diagrams are applied as standard diagrams for $[\mathrm{C}],[\mathrm{D}],[\mathrm{E}]$ and $[\mathrm{F}]$ in sono-powders mentioned above, and espetially, "Vi-effect" of mixed gases of dillute heliums with $\mathrm{H}_{2}$ display elements $\left(\mathrm{DH}, \mathrm{H}_{3},{ }^{3} \mathrm{He}\right)$ in mass $\mathrm{M} 3$ as shown in $\left[\mathrm{B}_{1}\right]$ and $\left[\mathrm{B}_{2}\right]$, and also using mixed $\left(\mathrm{D}_{2}+\mathrm{H}_{2}\right)$, elements $\left(\mathrm{DH}, \mathrm{H}_{3},{ }^{3} \mathrm{He}\right)$ and $\left(\mathrm{D}_{2}, \mathrm{DH}_{2},{ }^{4} \mathrm{He}\right)$ come in M3 and M4, respectively. Thus, these elements were formed in the case of "sono-powders" as shown in the middle and right side columns. In [B], because of dilution by excess hydrogens, only both $\mathrm{DH}$ and $\mathrm{H}_{3}$ were formed in mass $\mathrm{M} 3$, while using excess deuteriums in stead of hydrogens both $\mathrm{D}_{2}$ and $\mathrm{DH}_{2}$ come in mass M4. Thus in the case of mixed $\left(\mathrm{D}_{2}+\mathrm{H}_{2}\right)$ gases, elements $\left(\mathrm{DH}, \mathrm{H}_{3} ; \mathrm{D}_{2}, \mathrm{DH}_{2}\right)$ can be made in both $\mathrm{M} 3$ and $\mathrm{M} 4$, respectively, and also these elements were formed in the case of "sono-powders" as shown in above middle and right side columns. 


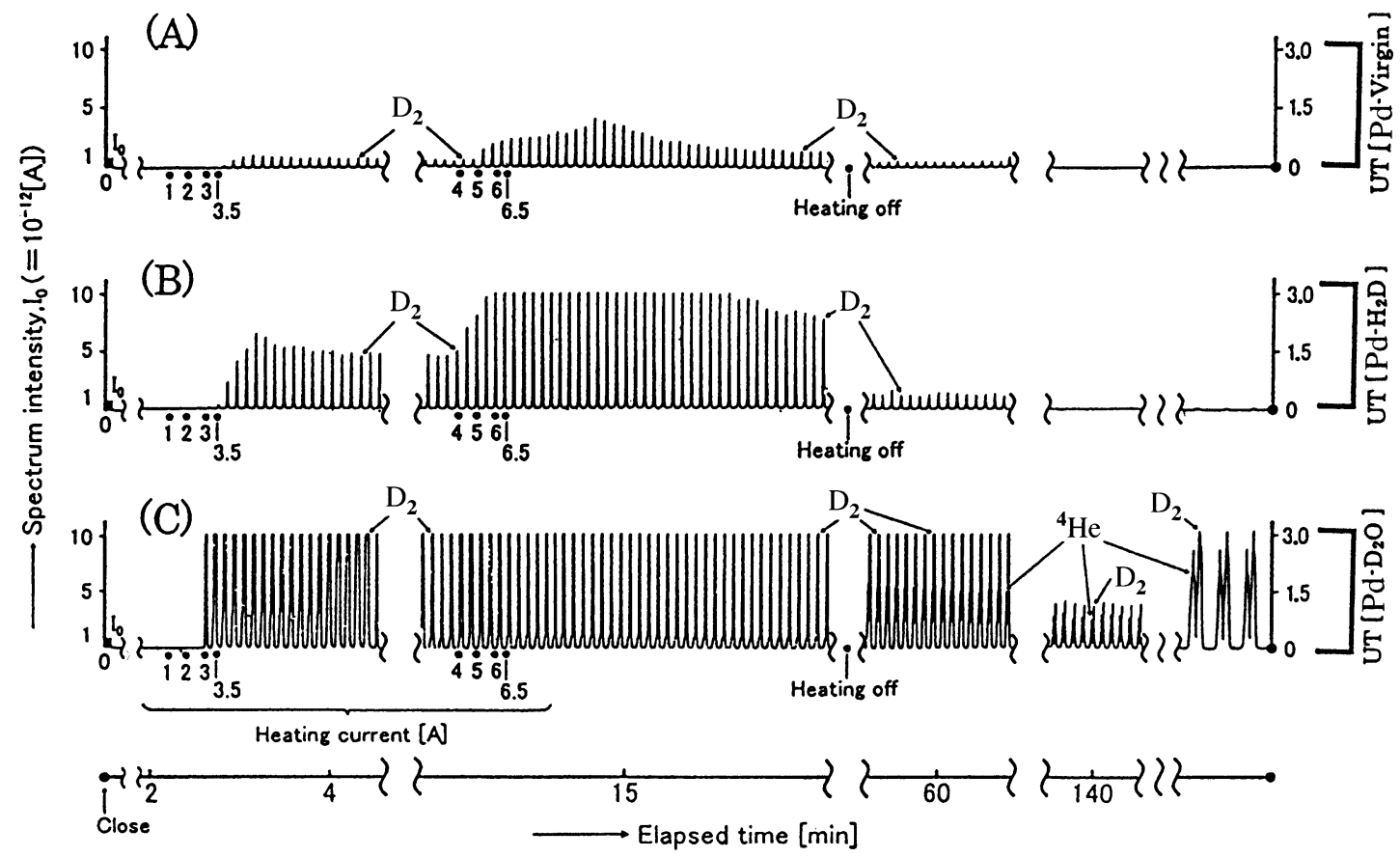

Fig. 5. Chronological changes of QMS spectrum-intensities of relevant mass $\mathrm{M}_{4}\left(\mathrm{D}_{2},{ }_{2}^{4} \mathrm{He}\right)$ in the sono-powders of Pd[virgin], $\mathrm{Pd}\left[\mathrm{H}_{2} \mathrm{O}\right]$ and $\mathrm{Pd}\left[\mathrm{D}_{2} \mathrm{O}\right]$

Here, DO* and $\mathrm{D}_{2} \mathrm{O}^{*}$ include $\left(\mathrm{CD}_{3}, \mathrm{CD}_{2} \mathrm{H}_{2}\right)$ and $\left(\mathrm{CD}_{4}\right)$ reflecting in D-implantation, respectively, and HO* includes $\left(\mathrm{CH}_{3} \mathrm{D}\right)$ in $\mathrm{H}$-implantation. It is concluded that comparison of implanted D and $\mathrm{H}$ atoms inside of metals should be using second group mass species. Consequently, the D-implantation is about a thousand times stronger than $\mathrm{H}$-implantation in general.

The D-implantation effect makes deeply condensed deuteriums higher than the host metal density during a short period. This event is basically important characteristic to cause the "sono-solid fusion". As a typical example in this case, reacted heliums $\left({ }^{3} \mathrm{He},{ }^{4} \mathrm{He}\right)$ are included in mass $\mathrm{M} 3\left(\mathrm{DH}, \mathrm{H}_{3}\right.$ and $\left.{ }^{3} \mathrm{He}\right)$ and $\mathrm{M} 4\left(\mathrm{D}_{2}, \mathrm{DH}_{2}\right.$ and ${ }^{4} \mathrm{He}$ ), respectively, as shown in Fig. 2 (C), (D) and (E). Hereafter, helium $\left({ }^{3} \mathrm{He},{ }^{4} \mathrm{He}\right)$ generated in the "sono-powders" called simply "sono-helium". On the other hand, simultaneously generated excess energy in the sonopowders were recognized in only $\mathrm{D}_{2} \mathrm{O}$-working liquid using the working liquids of $\mathrm{D}_{2} \mathrm{O}$ or $\mathrm{H}_{2} \mathrm{O}$-water, then these events are called simply "sono-excess energy" as described in following section.

a) Generation of "sono-excess energy". Fig. 3 shows excess energy generated inside the sono-vessel; $[\mathrm{A}]$ shows difference between "sono-generated energy" (sono-output/sono-current: $\left.\mathrm{Q}_{\text {out }} / \mathrm{I}_{\mathrm{imp}}\left(=\mathrm{Q}_{\bullet}\right) \quad[\mathrm{watt} / \mathrm{A}]\right)$ during formation of sono-powders (A:U[Pd], B:U[Ti], C:U[Au]) using $\mathrm{D}_{2} \mathrm{O}$ and $\mathrm{H}_{2} \mathrm{O}$-working liquids immersed the metal foils. [B] shows difference between sonoinput currents (shortly "sono-currents") changed with elapsed time[min] using the $\mathrm{D}_{2} \mathrm{O}$ and $\mathrm{H}_{2} \mathrm{O}$ working liquids, but these sono-currents were almost similar. Here, sono-generated energy $\left(Q_{\bullet}\right)$ was introduced by temperature difference between outlet $\mathrm{T}_{1}$ and inlet $\mathrm{T}_{0}$ $\left(\Delta \mathrm{T}=\mathrm{T}_{1}-\mathrm{T}_{0}\right)$ as shown in Fig. 1, but since a part of the sono-generated energy and/or "sono-excess energy" escapes as the loss from the sono-vessel to out-side through the "sono-vibrator", actually measured energy should be considerably lowered, so that because it is difficult to detect the actual loss energy, the "sono-excess energy" $\left(\Delta Q_{\bullet}[\right.$ watt/A] $)$, therefore, is given by the difference between "sono-generated energies" $\left(\mathrm{Q}_{\bullet}\left[\mathrm{D}_{2} \mathrm{O}\right]\right.$; Q. $\left.\left[\mathrm{H}_{2} \mathrm{O}\right]\right)$ generated in working liquids $\left(\mathrm{D}_{2} \mathrm{O} ; \mathrm{H}_{2} \mathrm{O}\right)$ as follows:

$$
\Delta \mathrm{Q}_{\bullet}=\mathrm{Q}_{\bullet}\left[\mathrm{D}_{2} \mathrm{O}\right]-\mathrm{Q}_{\bullet}\left[\mathrm{H}_{2} \mathrm{O}\right]
$$

where, $\mathrm{Q}_{\bullet}=$ (sono-input energy + sono-excess energyloss energy)/sono-current.

It is concluded that using intense sonoimplantation effect for the many kinds of metal foils, both sono-excess energy and sono-helium $\left({ }^{3} \mathrm{He},{ }^{4} \mathrm{He}\right)$ generated simultaneously with formation of their nanometer-sized powder 
("sono-powder") with extraordinary D-atoms or mixed $\mathrm{H}$-atoms, so that we named "sono-solid fusion" for these events.

b) Generation of "sono-helium". Fig. 4 shows relation between applied ionization voltage (V[V]) and spectrum intensity current (I[A]), (called simply "VI-relation"), ${ }^{3)}$ measuring relevant masses M3 and M4 in such sono-powders as $\mathrm{Pd}\left[\mathrm{D}_{2} \mathrm{O}\right], \quad \mathrm{Ti}\left[\mathrm{D}_{2} \mathrm{O}\right], \quad \mathrm{Ag}\left[\mathrm{D}_{2} \mathrm{O}\right]$ and $\mathrm{Au}\left[\mathrm{D}_{2} \mathrm{O}\right]$. Here, the applied voltage is changed automatically from $17[\mathrm{~V}]$ to $40[\mathrm{~V}]$ through several times (for example; first: 30 [min] later, second: 1 [hr], third: 3 $[\mathrm{hr}], \cdots)$ after finished heating of the sono-powders using normal type QMS, but another type of high resolution QMS is no changed to keep constant 70[V]. Fig. 4 [A] shows "VI-relation" in both M3 and M4 of almost equally mixed gases released from pure ${ }^{3} \mathrm{He}$ and ${ }^{4} \mathrm{He}$ gas tank. Fig. 4 [B] shows case of the mixed gases diluted by much hydrogens ( 100 times) for helium gases of Fig. 4 [A], and such similar patterns of Fig. 4 [B] appear fluently in the sono-powders, as shown in Fig. 4 [C], [D], [E] and [F], respectively. In the Fig. $4[\mathrm{~A}]$ and $[\mathrm{B}], \mathrm{A}_{0}$ and $\mathrm{B}_{0}$ show normal "VI-relation", and $\mathrm{A}_{1}, \mathrm{~A}_{2}, \mathrm{~B}_{1}$ and $\mathrm{B}_{2}$ demonstrate "VIrelations" indicating the intensity current changed per 2 voltage at each applied voltage. Hereafter, $A_{1}$ and $B_{1}$ diagrams called simply "Vi-effects" and $\mathrm{A}_{2}$ and $\mathrm{B}_{2}$ called normalized-"Vi-effect". ${ }^{3)}$ Characteristic of both "Vi-effect" can contribute greatly to separate each other elements of $\mathrm{DH}, \mathrm{H}_{3}$ and ${ }^{3} \mathrm{He}$ in $\mathrm{M} 3$, but it is not so easy in case of separating these elements using only high resolution spectrums. As a result, using "Vi-effect" and normalized-"Vieffect", existence and amount of each element such as ${ }^{3} \mathrm{He},{ }^{4} \mathrm{He},{ }^{22} \mathrm{Ne}$, etc. can be clearly displayed, so that Fig. 4 shows existence and amounts of "sono-helium" ( ${ }^{3} \mathrm{He}$ and ${ }^{4} \mathrm{He}$ ) generated as reaction products in the "sonosolid fusion".

Fig. 5 shows relation between amount of $\mathrm{D}_{2}$ (sonoimplanted D-atoms) and generation of "sono-helium ${ }^{4} \mathrm{He}$ ", using spectrum-intensities of relevant mass $\mathrm{M}_{4}$ generated in the sono-powders which were made under condition of the different working liquids $\left(\mathrm{D}_{2} \mathrm{O} ; \mathrm{H}_{2} \mathrm{O}\right)$ for the same $\mathrm{Pd}$ metal foils. As a result, it was clarified that only sono-powder $\left(\mathrm{Pd}\left[\mathrm{D}_{2} \mathrm{O}\right]\right)$ applied $\mathrm{D}_{2} \mathrm{O}$-working liquid generated extraordinary amount of sono-implanted Datoms and "sono-helium", but never in sono-powder $\left(\mathrm{Pd}\left[\mathrm{H}_{2} \mathrm{O}\right]\right)$ applied $\mathrm{H}_{2} \mathrm{O}$-liquid and also $\mathrm{Pd}$ [virgin]. These events are very important to know existence of "sonosolid fusion", and similar events in other metals were also recognized.

Acknowledgments. The authors would like to thank Dr. K. Sugimoto and Dr. T. Yamazaki (Professors Emeritus at the University of Tokyo), Dr. H. Fujita (Professor Emeritus at Osaka University), and Dr. T. Yokobori, M. J.A. (Professor Emeritus at Tohoku University), for their strong interest and kind discussions on this research. They also thank Dr. S. Miyake (Professor, Osaka University), and Dr. M. Futamata (Professor, Kitami Institute of Technology), for their interest in this research.

\section{References}

1) Arata, Y., and Zhang, Y.-C. (1998) Proc. Japan Acad. 74B, 201205; (2001) Proc. Japan Acad. 77B, 43-46.

2) Arata, Y., and Zhang, Y.-C. (2000) Appl. Phys. Lett. 76, 2472 2474; (2002) Appl. Phys. Lett. 80, 1-3.

3) Arata, Y., and Zhang, Y.-C. (1997) Proc. Japan Acad. 73B, 1-6. 